\title{
Energy management of commercial buildings - A case study from a POET perspective of energy efficiency
}

\author{
Xiaohua Xia \\ Jiangfeng Zhang \\ Centre of New Energy Systems, Department of Electrical, Electronic and Computer Engineering, \\ University of Pretoria, South Africa
}

William Cass

FirstRand Group, Sandton, South Africa

\begin{abstract}
This paper aims at analyzing the energy management activities for commercial buildings of a financial service company in South Africa by energy efficiency in terms of performance, operation, equipment and technology (POET). The sustainability of a general energy management program is discussed within this POET framework. As an application of this discussion to the commercial building scenario, the award winning energy management program of this financial service group company is featured from the POET perspective of energy efficiency. The case study shows that the POET based framework can not only cover all major energy management activities, but also identify further energy efficiency improvement opportunities.

Keywords: energy management, energy efficiency, commercial building
\end{abstract}

\section{Introduction}

In order to reward exceptional effort in energy efficiency improvement in South Africa, the main electricity supplier Eskom and the Department of Minerals and Energy have hosted the eta Awards for 20 years. A financial service group company was one of the winners in 2009 because its completed projects in the energy management of almost 900 buildings had delivered 7.5 million South Africa Rand (ZAR) annual saving while planned initiatives would deliver a further 8.1 million ZAR annual saving. The company has established energy dashboards for its large buildings to track current energy consumption against historical baselines and thus to facilitate its targeted $11 \%$ of electricity consumption reduction per building by 2012. The study on the energy management activities of this company will not only help its further energy efficiency improvement, but also benefit general energy management programs.

Recently we have summarized different energy efficiency components into performance, operation, equipment and technology (POET) efficiencies, and presented applications of this classification in heavy-haul trains (Xia and Zhang, 2011), control systems (Xia and Zhang, 2010a), and energy audit (Xia and Zhang, 2010b). The POET framework provides a general conceptual classification to include different views for energy efficiency improvement. Existing applications in heavy-haul trains, control systems and energy audit reveal that the POET approach is able to identify missing energy efficiency improvement opportunities in a general practical project. Stimulated by these applications, this paper aims at analyzing the energy management activities of the above mentioned South African financial service company from a POET perspective.

For this purpose, this paper will briefly recall from (Xia and Zhang, 2010a) the POET based energy management basics in the next section. Subsection 2.3 provides a number of criteria for the sustainability of an energy management program. Then the energy management activities of the financial service company are analyzed from the POET perspective in Section 3. Concluding remarks are drawn in the last section.

\section{Basics of POET framework of energy efficiency}

The following Subsection 2.1 and 2.2 are taken from (Xia and Zhang, 2010a) and (Xia and Zhang, 2010b) with minor revisions. 


\subsection{POET definitions}

Energy efficiency is a measure of useful energy output versus energy input, and it comes in four levels: technology, equipment, operation, and performance.

Performance efficiency of an energy system is a measure of energy efficiency which is determined by external but deterministic system indicators such as energy security, production, cost, energy sources, environmental impact and technical indicators amongst others.

Operation efficiency is a system wide measure which is evaluated by considering the proper coordination of different system components. This coordination of system components consists of the physical, time, and human coordination parts. Operation efficiency has the following indicators: physical coordination indicators (sizing and matching); time coordination indicator (time control); and human coordination.

Equipment efficiency is a measure of the energy output of isolated individual energy equipment with respect to given technology design specifications. The equipment efficiency is usually considered being separated from the system and having little interactive effect to other equipment or system components. Equipment efficiency is evaluated by considering the following indicators: capacity; specifications and standards; constraints; and maintenance. Equipment efficiency is specifically characterized by its standardization and constant maintenance.

Technology efficiency is a measure of efficiency of energy conversion, processing, transmission, and usage; and it is often limited by natural laws such as the energy conservation law. Technology efficiency is often evaluated by the following indicators: feasibility; life-cycle cost and return on investment; and coefficients in the conversing/ processing/transmitting rate (Weston, 1992)

Technology efficiency is a deciding factor to

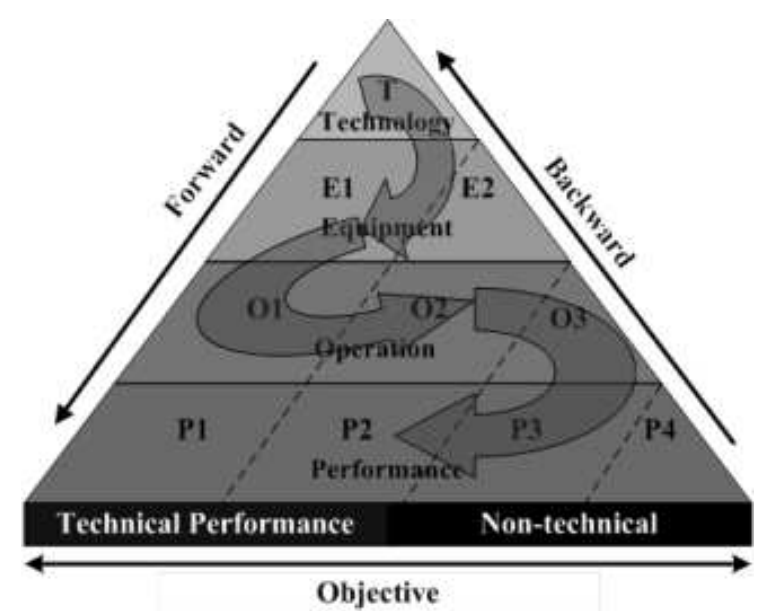

Figure 1: Energy efficiency components equipment, operation, and performance efficiencies as illustrated by Figure 1. The deterministic relationships further decompose the POET components. In Figure 1, equipment efficiency has two parts E1 and E2. E1 represents the kind of equipment efficiency directly affected by technology efficiency such as the differences between output energy and equipment specifications, while E2 is the part not directly affected by technology efficiency such as equipment maintenance. Similarly one can define the blocks $\mathrm{O} 1, \mathrm{O} 2$, O3, P1, P2, P3, and P4. For example, $\mathrm{O} 2$ is the part determined by $\mathrm{E} 2$ in equipment efficiency, and it can be the relevant system component coordination for equipment maintenance, the time related operational strategies for efficiency improvement, or other factors determined by E2.

\subsection{Activities in the POET based energy management}

Generally, an energy management program consists of three processes: energy auditing, energy targeting, and energy planning. Energy auditing is the process to profile energy consumption and to identify the energy saving opportunities. Through this process, a rough objective or target such as possible percentage of energy savings or energy efficiency improvement can often be figured out, and one may determine a reasonable target according to this obtained energy audit result. The process to determine such a reasonable energy efficiency improvement target is called energy targeting. Energy planning process focuses on the detailed energy efficiency improvement plans and it includes also energy policy support, organization structures and implementations. There are no clear-cut boundaries among energy auditing, energy targeting and energy planning. An energy management program can be classified into four levels: conceptual level, active level, technical level, and engineering level.

The conceptual level energy management is characterized by 'identification' as most of the activities involved are simple but effective identification which can be roughly analogized as the '80-20' rule implying a $20 \%$ of effort with a $80 \%$ of profit. This kind of identification can often be finished by an energy manager through analyzing the energy system components and energy consumption utility data, even without adding more meters for data collection and thorough data statistics and analysis.

The active level of energy management implies that further effort other than the '80-20' rule must be put, and it is often that existing energy data may not be enough and additional metering is needed. After collecting enough data, the previously established conceptual energy management strategies will be improved and validated, therefore, this stage is featured by 'validation'.

The technical level energy management is featured by the implementation of the initiatives and 
the verification of the claimed energy savings, and it may include new energy technologies; system retrofitting, automation and control; metering; creating a baseline; monitoring, evaluating, calculating energy usage; and verifying saving targets.

The engineering level energy management involves advanced energy system modelling, benchmarking/baselining, and optimization. The engineering cycle in its content may overlap with the technical cycle at the strategic level, but it is often used to provide a technical viability analysis for the energy system. Making dedicated engineering comparisons, combinations, and optimization of technical solutions may be included in this level (Middelberg, et al, 2009), (Rajan, 2006).

\subsection{Sustainable energy management program based on the POET framework}

The sustainability of an energy management program can be measured by the following three aspects.

\section{(i) Organizational structure}

A sustainable energy management program is always supported by a good organizational structure. For instance, relevant policies, regulations, incentives, competitions, awards, penalties, and human sensitization can greatly stimulate the POET efficiencies and thus the sustainability of energy management programs. This is evident from the example that a time-of-use electricity tariff will promote the load shifting from peak hours, which alleviates the burden of electricity suppliers and improves the operation efficiency of the whole network. Awareness campaign, energy alert, procedural guidance of work flow, skill training, production exhibition, technology road show, appointment of energy managers, etc, are important for human sensitization to support and promote energy management programs.

\section{(ii) Compatibility of performance indices}

Energy system performance efficiency indicators can generally be classified into engineering indices and socio-economic indices. For instance, engineering indices include energy security, energy sources, energy consumed, and other technical indicators; while socio-economic indices include quality of production, energy cost, labour, environmental impact, etc. Sometimes engineering indices may compete with socio-economic indices, and indicators within engineering indices or socio-economic indices may also compete with each other. For instance, carbon emission and production are contradictive socioeconomic indicators, and the purpose of saving energy also contradicts the intended increase of production. A good example of sustainability is to have a win-win compliance among all these engineering and socio-economic performance indices.

\section{(iii) Engineering support}

Engineering analysis, modelling and optimization are key issues to provide technical viability analysis for an energy system. With engineering support, an energy management program will provide more reliable energy solutions which drive the energy system in a more sustainable way.

\section{Case study \\ 3.1. Background}

Cheap and reliable electricity for industrial use was one of South Africa's most important competitive advantages. This is no longer the case and the damage it has caused to South Africa's international reputation and national self-confidence has been incalculable. In January 2008, huge blackouts occurred throughout the country. The national grid almost crashed. In order to prevent this, an urgent Power Conservation Program (Department of Minerals and Energy of South Africa, 2008) has been implemented in which top electricity consumers are expected to reduce $10 \%$ electricity consumption compared with the reference annual consumption from October 2006 to September 2007. Although this Program is not mandatory, many companies are proactive to this Program, and as a result the pressure on the electricity grid has temporarily eased. However, there will be a very little reserve margin with a constant threat of power outages for at least the next five years.

In South Africa, coal-fired power stations supply 92\% of electricity in South Africa, and the corresponding carbon emission makes South Africa's $\mathrm{CO}_{2}$ emission per unit of GDP among the highest in the world (International Energy Agency, 2009). Actively reducing negative impact on the environment will help a company to get better support from all stakeholders as it shows vision, good corporate citizenship and the intention to be trading in the long term.

The main electricity supplier Eskom had increased its electricity tariffs in 2009 and will continue to increase the tariffs in the following years. The new government policy on Tax Incentive (National Treasury of South Africa, 2009) allows a certain amount of tax rebate if the energy efficiency improvement is $12 \%$ at least in an energy management program. There are also numerous other incentives for energy efficiency projects from the South African government. Thus, a good energy saving plan will save quite a lot of energy cost. Furthermore, the reduction in energy consumption will release to a certain extent the pressure of the main grid and eventually attenuate the possibility of power outage.

As one of Eskom's major customers, this financial service company is very proactive to reduce $10 \%$ of its energy consumption following the request of the Power Conservation Program in 
2008. In October 2008, a branch company has suffered a one week long power outage. Based on the justifications of power outage threats, environmental concerns, the energy saving incentives, the Power Conservation Program, and the experience of economic losses in the one week power outage, this financial service company commits to have backup power at key sites to minimize the impact of power outages and to implement an extensive energy management program to improve energy efficiency. It further commits to reduce $11 \%$ of electricity consumption per building by 2012 against the baseline electricity consumption during the period from October 2006 to September 2007.

To this end, a comprehensive energy management program has been implemented in this company which will be analyzed in the POET framework in the following subsections.

\subsection{Organizational structure}

Organizational supports to the energy management program of this company are listed below.

- Policies/incentives: The Tax Incentive program is an external incentive for energy efficiency investment and improvement, and a branch bank within this company has committed to fund retrofits under its current 'Cashflow Payback' product.

- Regulations/penalties: Branch companies have been required by the company headquarters to implement the energy management program and to save $11 \%$ energy per building.

- External technical support: External technical support has been sought to investigate energy efficiency opportunities and new technologies such as solar water heating systems and heat pumps.

- Human sensitizations: Top management buy-in is adopted to emphasize energy efficiency, an energy manager is appointed to establish and handle the whole energy management program, the proposed energy strategies have been accepted and implemented, the Energy Forum meets on a quarterly basis to discuss energy issues, the Energy Dashboards are created to incentivize and 'name and shame' business units, commitment and support from the company CEO are obtained, and all subgroup companies are committed.

\subsection{Compatibility of performance indices}

In the existing energy management program of this company, the main energy saving initiatives generally have payback periods less than three years. The profit becomes available after three years, and it will further stimulate the implementation of more energy efficiency improvement initiatives by providing saving opportunities and funding support for new initiatives. From this sense, this company has suc- cessfully achieved both the financial and technical viabilities which contribute to the sustainability of the program.

The energy management program of the company focuses on the investment of back up power, the purchase of energy efficient equipment, the adjustment of air conditioner settings, the building management system, variable speed drives, power factor correction, computer energy saving settings, lighting retrofit, and motion sensors. Therefore, the energy demand and production of the company have not been affected by the program, the energy consumption and energy cost have been reduced, and the green house emission has been decreased accordingly. The reduction of energy consumption is mainly due to the energy efficient equipment and the control of energy waste. The corresponding energy cost saving shows a compatibility of the performance efficiency indicators such as normal production rate, electricity consumed, and the return of investment amongst others. In all, the company has achieved a good balance among engineering and socio-economic indices.

\subsection{Engineering support}

The engineering support to the energy management program of this company is analyzed in this subsection by considering major POET efficiency components and indicators in the conceptual, active, and technical levels of energy management. The engineering level of energy management for this company is not studied as it involves many research problems and is not applicable to the existing energy management program of this company.

\subsubsection{Conceptual level}

The conceptual level of energy management activities of this company are analyzed as follows.

\section{- Technology efficiency}

Electricity consumption data is analyzed using a pie chart. Through analyzing the electricity consumption of different system components in major buildings, Figure 2 is obtained. This figure shows that air-conditioning is the largest consumption and occupies $40 \%$ of the total energy consumption; light-

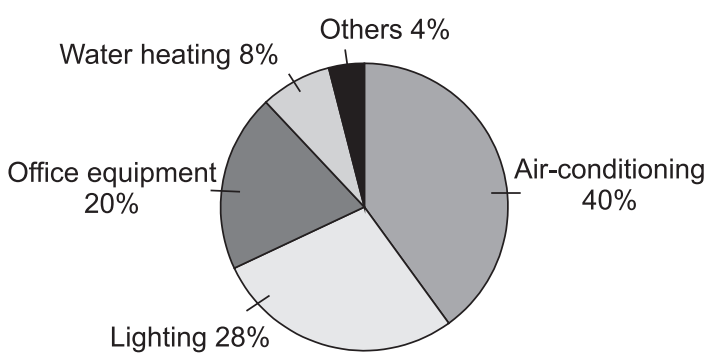

Figure 2: Energy consumption in commercial buildings 
ing is the second largest consumption and occupies $28 \%$ of total consumption; and office equipment and water heating occupy $20 \%$ and $8 \%$, respectively, of the total energy consumption. Therefore, the energy management focus will be on the four categories: air conditioning system, lighting system, office equipment and water heating system.

Following the results of energy data analysis, Figure 3 is obtained to show the payback periods and the corresponding percentage savings of total energy consumption of different technology renovations. For the purpose of financial viability, the company prioritizes the implementation of the initiatives with payback periods not exceeding three years which are indicated in Figure 3 as 'Quick wins' or 'Low hanging fruit'.

\section{- Equipment efficiency}

Since technology efficiency helps to determine that energy efficient lights, motion sensors, variable speed drives, power factor corrections, etc, are the main technology used in the program, the relevant equipment is purchased and installed. For instance, incandescent lights are replaced by compact fluorescent lights to improve equipment efficiency; cathode ray tube (CRT) computer monitors are replaced by liquid crystal displays (LCD) to save energy; and power factors are corrected to reduce the maximum demand charge.

\section{- Operation efficiency:}

The operation efficiency has been improved in many aspects. For example, air conditioning temperature settings are adjusted a little higher to reduce the demand on cooling air which saves energy and improves performance efficiency; elevators are switched off at night; one chiller is switched on after 11:00 am; computers are remotely shut down at non-working hours; and motion sensors and building monitoring systems will switch off unnecessary lights during un-occupied hours.

\section{- Performance efficiency}

The first level of performance efficiency is energy security. Without a secured energy supply, it is meaningless to discuss energy efficiency. To this end, this company has extended backup power storage to reduce the risk of power outage. The commercial buildings are classified into different categories according to their functions: strategic function, front line function and cheque processing, and support function amongst others. The minimum standby capacity for different functioning categories are recommended, for instance, for buildings with the strategic function the recommended minimum standby power capacity is 10 days, while for buildings with support functions the minimum capacity is 2 days. This company stores approximately 474000 litres of diesel at large sites, with a further 300000 litres of diesel at off-site facilities. The diesel usage will be prioritized in case of an electricity outage.

Besides energy security, the energy consumption indicator is considered, and a target of $11 \%$ total energy consumption saving against the baseline year after the implementation of the energy management initiatives has been placed by the company. Furthermore, staff awareness arising from

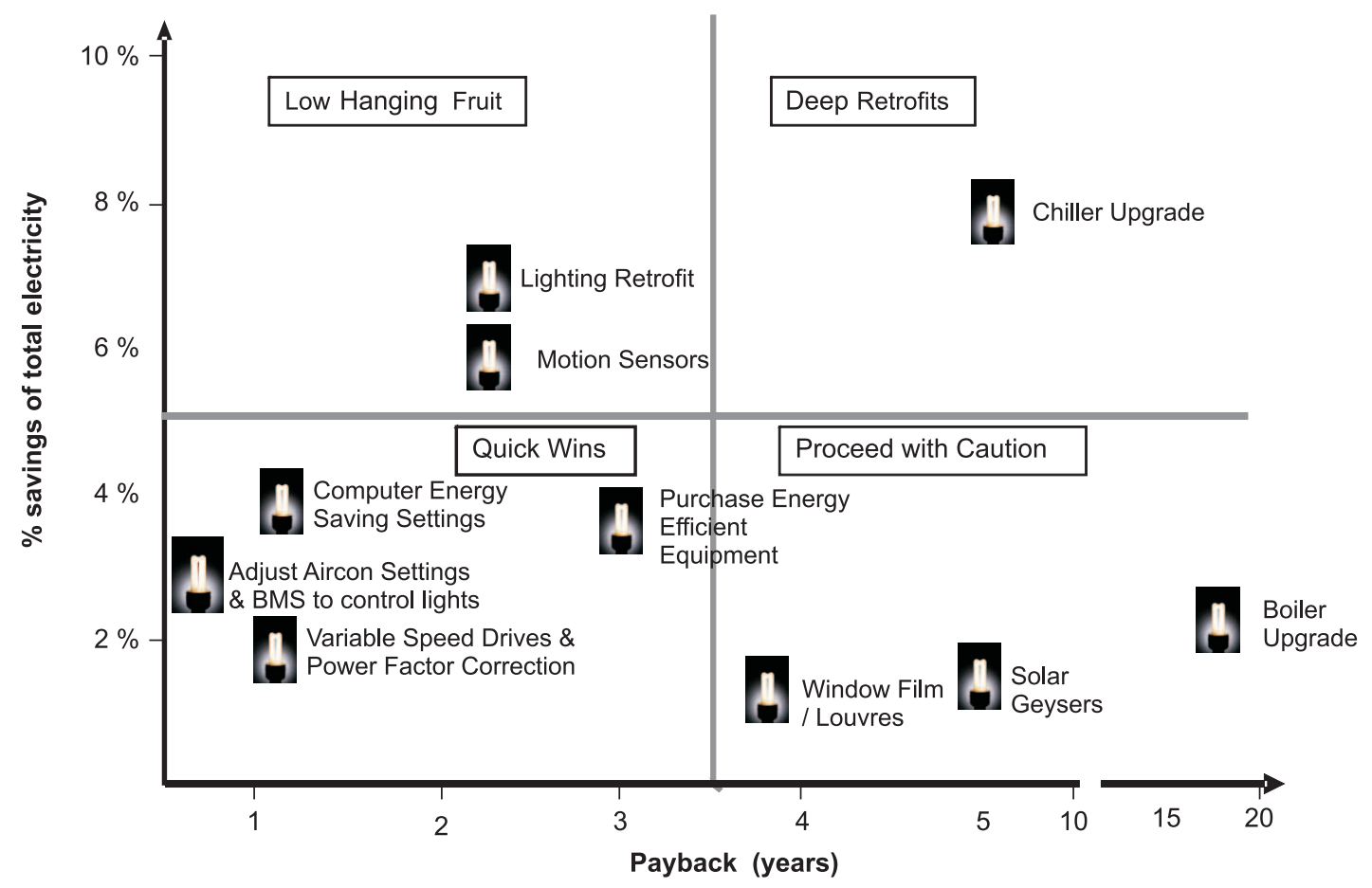

Figure 3: Energy saving initiatives: percentage saving versus payback period 
campaign for energy saving is held by a weekly email newsletter and a monthly staff magazine to improve both performance and operation efficiency; and different diesel suppliers are contacted to ensure the cheapest possible diesel price.

\subsubsection{Active level}

The active level energy management of this company can be analyzed below.

\section{- Technology efficiency}

New technology for possible future energy saving initiatives is tested, and the tested technology includes variable speed drive, the online energy alerting software PowerWatch which is based on telemeters (www.my-powerwatch.com), and the fluorescent lighting control system LightEco Plus (www.fairfordenergy.co.uk/light-eco-plus) amongst others.

\section{- Equipment efficiency}

New equipment has been installed at this stage. This includes the installation of intelligent telemeters to collect real time energy consumption information, replacement of air-conditioning fan motors, installation of the Building Management System, LightEco Plus control system, variable speed drive motors for fans, geyser timers and window films or louvers, etc. Insulation from roofs to walls and windows, and double glazing on the windows are adopted to reduce heat exchange through building envelopes. Inefficient equipment, such as starters and deactivate capacitors in old light fittings and high power factor magnetic or electronic ballasts, are removed.

\section{- Operation efficiency}

During the design of new buildings or the retrofitting of exist buildings, it is encouraged to allow as much as possible natural light filtering into the buildings. In order to take a good advantage of skylights, the furthest distance of a workstation from a perimeter window or light well is 15 meters. Automated Shut Down software and other energy saving settings are installed in computers, and these bring R100 to R250 electricity saving per computer per year. Relevant staff is also trained to efficiently use office equipment, control the geyser timers and set the air-conditioner temperatures.

\section{- Performance efficiency:}

For the energy security problem, this company establishes a database for all buildings with details of generators, Uninterruptible Power Supply (UPS), diesel storage capacity and standby capacity. Statistics for current diesel storage, the standby power capacity in days, and recommended diesel purchase are listed for each building. The branch company which suffered a one week long power outage in 2008 had been investigated, and problems discovered included the fuel pump failure, fuel supply to the day tanks failure, and inefficient lighting during power outage. These problems were quickly solved to ensure secure backup power supply.

Since the energy management program has made the target of $11 \%$ energy saving, this energy saving has been further broken down into the savings of different energy saving initiatives. For instance, in order to achieve this $11 \%$ target, the installation of motion sensor will contribute about $6 \%$, the retrofitting of lights will contribute $7 \%$, the adjustment of air conditioner settings and the Building Management System for the lights control will contribute $2-3 \%$, the computer energy saving settings will contribute $4 \%$, etc. From this broken down information, the $11 \%$ target will be easily fulfilled. For each initiative, it is further broken down into two phases: the implemented initiative and the planned initiative. The achieved savings in implemented initiatives up to September 2009 and the remaining target in planned initiatives are calculated to facilitate the management.

\subsubsection{Technical level}

The technical level energy management activities of this company are summarized as follows.

\section{- Technology efficiency}

The technique of establishing an energy dashboard for each major building is employed. A simplified energy dashboard example consisting of one diagram and three tables is given in Figure 4. It provides the comparison of the baseline and actual energy consumption, the tracking of implemented initiatives, planned initiatives and standby capacities. Note that the baseline consumption in Figure 4 is the energy consumption during the period from August 2006 to July 2007, and this baseline is only a snapshot of the electricity consumption for the ease of decision makers to figure out the estimated savings. A reasonable baseline needs to be dynamically adjusted according to service level changes, and it can be obtained following the discussion on measurement and verification in Section 3.5. A full version energy dashboard contains much more information than Figure 4, and it often includes information on all the implemented energy initiatives in terms of project names, cost centre numbers, project types (e.g., new outlet, upsizing, relocation, and revamp), project starting dates, design and planning dates, operating model approval dates, security approval dates, IT costing/HVAC/ Electrical drawing and billing dates, total investment cost, expected and actual savings, payback time, etc.

Secondary voltages at substations have been optimized through the measurement of voltages 


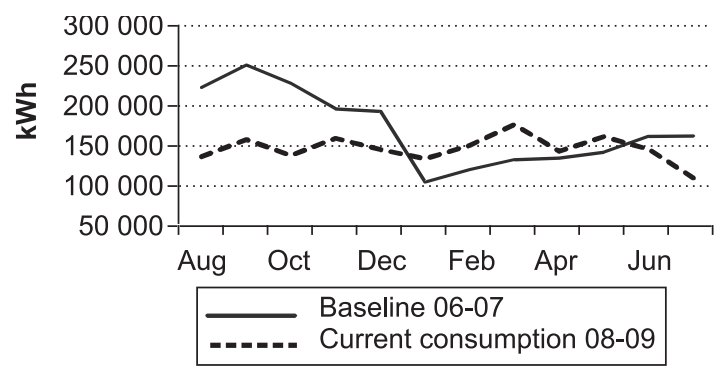

Tracking of implemented Initiatives

\begin{tabular}{lccc}
\hline Initiative & Date implemented & Implementation cost & Actual savings \\
\hline $\begin{array}{l}\text { Switching off the } \\
\text { escalators of at night. }\end{array}$ & $09 \mathrm{Mar}$ & R0 & R 137446.00 \\
\hline
\end{tabular}

\begin{tabular}{lccc}
\hline Planned initiatives & & & \\
\hline Initiative & Expected live date & Implementation cost & Payback period (years) \\
\hline Solar panels installation & $09 \mathrm{Apr}$ & & \\
\hline & & & \\
\hline Standby capacity & & Diesel capacity & Standby capacity \\
\hline UPS' & Generators & 52500 & 5 days \\
\hline $8 \times 200$ & $6 \times 1350$ & & \\
\hline
\end{tabular}

Figure 4: Energy dashboard example

more than 405 volts and the reduction of 14 transformer steps into one step. This leads to $5 \%$ electricity saving and a saving of more than R70 000 per month. The software Power Optimisa (www.poweroptimisa.com) is further tested to normalize voltage. SmartCool System (www.smartcool. net) is also investigated to reduce HVAC compressor load by $15-25 \%$.

Further investigations on the detailed design to roll out other new technologies such as solar water heating systems, photovoltaic system for electric fence and decorative lights, and heat pump water heaters have been carried out to identify more energy saving potentials.

\section{- Equipment efficiency}

Some of the technologies identified through technology efficiency investigation have been implemented. For instance, solar geysers, photovoltaic systems, and heat pump water heaters are installed; some of the air-conditioners, chillers and boilers are upgraded into energy efficient ones.

\section{- Operation efficiency}

The implemented energy initiatives need to be operated properly and efficiently. Staff members were trained to the proper use of the installed new equipment systems.

\section{- Performance efficiency}

The Energy Dashboard is a good tool to monitor the energy consumption indicator in performance efficiency. For instance, Figure 5 shows the comparison of current energy consumption with the baseline energy consumption at a branch company, while Figure 6 shows the difference between actual energy consumption reduction and the targeted $11 \%$ energy consumption saving in the same branch company. Figure 6 implies that the $11 \%$ target of energy saving has already been reached in this branch company. The consumption information given in these figures also promotes the energy saving awareness for the building occupants.

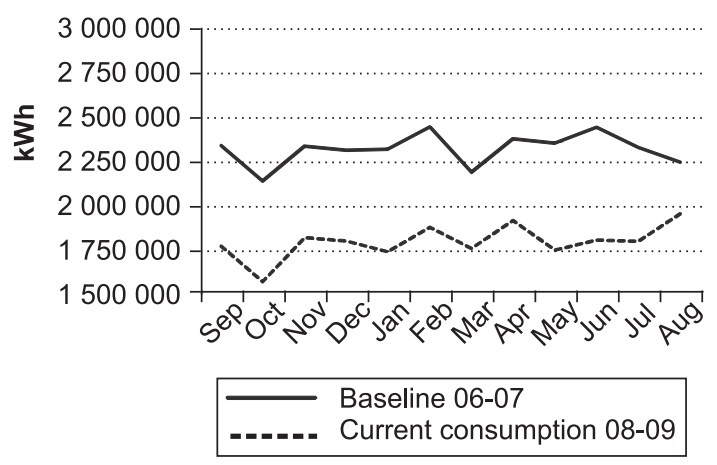

Figure 5: Baseline versus actual energy consumption

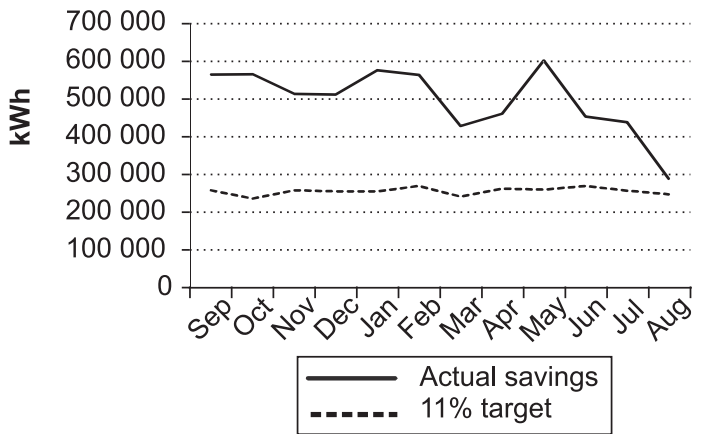

Figure 6: $11 \%$ reduction targets versus actual reduction 


\subsection{Possible improvement}

The energy management program of the company is very comprehensive and covers most of the important aspects in energy efficiency. Under the POET framework, it still has the potential to be further improved. The following lists some of the possible improvements.

\section{- Technology efficiency}

The Energy Dashboard can be improved by adding the relevant information on a system simple maintenance schedule which is obtained by data analysis and experience and without any system modelling or optimization; remaining time to payback the investment; etc.

Advanced building automation systems can be investigated to optimally and dynamically change the air-conditioning temperature set point according to real time weather conditions and occupancy level, energy rate, and energy consumption saving objectives amongst others. Wind turbines, geothermal heat pumps, air to air heat pumps, etc, are also good options which can be further tested to improve energy efficiency.

The applications of Measurement and Verification $(\mathrm{M} \& \mathrm{~V})$ technique will provide a reliable result on the actual savings. The $\mathrm{M} \& \mathrm{~V}$ in terms of the International Performance Measurement and Verification Protocol (IPMVP) (Efficiency Valuation Organization, 2007) provides a strict and reliable measurement on the savings. For instance, the company determines its energy saving by a direct comparison of the current energy consumption with the baseline year consumption. This is sometimes not a very fair comparison from the $M \& V$ point of view as illustrated in the case of Figure 7. Figure 7 gives the comparison of actual energy consumption of a branch company after energy initiative implementation with a baseline consumption. From June 2008 to September 2008, the energy consumed is less than the corresponding period in the baseline; however, the energy consumed after implementation increased sharply from October 2008 and con-

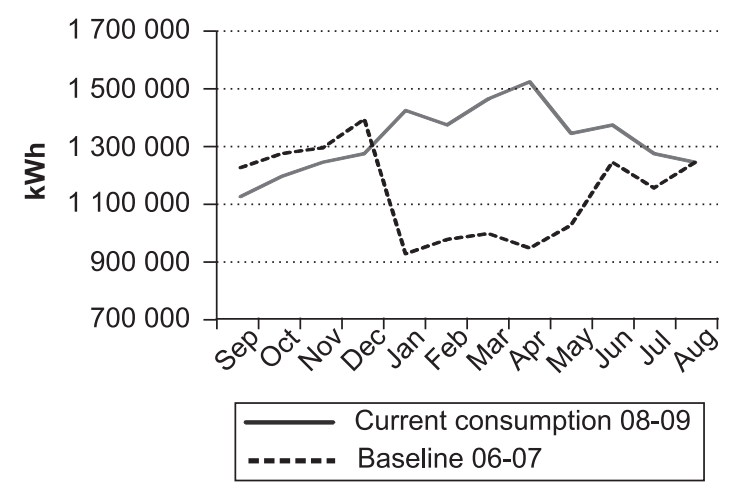

Figure 7: Actual consumption versus the baseline sumed much more energy than the baseline. It will not be fair to claim the failure of the energy saving initiatives for this branch company as the production level may be different before and after the implementation. The IPMVP provides a comprehensive guide to adjust the baseline consumption so that the adjusted baseline will have the same external environment (e.g. production level and weather variables) as the situation after implementation.

\section{- Equipment efficiency}

Equipment efficiency can be improved by the development and implementation of a well designed equipment maintenance plan. This includes the regular maintenance of the electrical systems including electric geysers and light bulbs, the heating and ventilation systems, the air-conditioning system, the heat recovery system, the renewable energy system and the back up power supply system amongst others. The maintenance activities should be recorded in the Energy Dashboard.

\section{- Operation efficiency}

The operation efficiency can be improved by various energy system optimization skills. For instance, the operation timetable of an HVAC system can be optimized by incorporating the maintenance schedule, occupancy level, ambient temperature and moisture, etc. Besides the existing load shifting plan in chillers, more load shifting plans involving geysers and other energy storage facilities can be made.

\section{- Performance efficiency}

The energy management program has the target of $11 \%$ of energy saving for each building, and this target has been allocated to the sub-targets savings of different initiatives, for instance, $6 \%$ saving from motion sensor installation and $7 \%$ from light retrofitting. The allocation of these sub-targets can be further optimized by incorporating the financial budget constraints, the payback time, and the retrofitting time.

The information provided in the existing Energy Dashboard can be further expanded. In fact, all the major performance efficiency indicators such as energy cost, energy waste, carbon emission, staff knowledge and skill level, life cycle cost, and return of interest amongst others can be added in the dashboard.

There are also the following initiatives which can be used as supplementary to the current initiatives. For example, external driving forces from the government including controlled list of inefficient products, appliance labelling and feed-in tariff can further stimulate energy management programs, and the company headquarter can also impose similar 
strategies to branch companies. The sensitization such as the work flow procedural guidance and the corresponding training; product exhibition and accredited professionals; and technology road show and related high education will improve further the existing energy management program.

\section{Conclusion}

This paper studies an energy management program for commercial buildings from a newly proposed POET approach. This POET approach defines three criteria for the sustainability of an energy program: organizational structure, compatibility of performance indices, and engineering support. Based on the three criteria and the POET efficiency indicators, the energy initiatives of this company are analyzed and possible energy efficiency improvement opportunities are found. This case study shows the prosperous future application of this POET framework in general energy management projects. Note further that the main focus of this paper is on the application of POET framework on energy management, while the corresponding application on measurement and verification for baseline and savings determination has not been discussed. As a future work, this application in measurement and verification will be investigated.

\section{Acknowledgements}

The authors would like to thank the anonymous reviewers for their valuable comments.

\section{References}

Department of Minerals and Energy of South Africa (2008). National response to South Africa's electricity shortage, Available: www.dme.gov.za/pdfs/energy/ national_resp_plan.pdf.

Efficiency Valuation Organization (2007). International Performance Measurement and Verification Protocol, Volume 1, EVO 10000-1.

International Energy Agency (2009). $\mathrm{CO}_{2}$ Emissions from Fuel Combustion 2009 - Highlights, OECD/IEA, Paris.

Middelberg A., Zhang J., and Xia X. (2009). An optimal control model for load shifting- With application in the energy management of a colliery, Applied Energy, Vol. 86 pp1266-1273.

National Treasury of South Africa (2009). Draft regulations under Section 12I of the Income Tax Act, 1962 (Act No. 58 of 1962), www.treasury.gov.za.

Rajan G.G. (2006). Practical Energy Efficiency Optimization, PennWell Books, Tulsa.

Weston K.C. (1992). Energy Conversion, PWS Pub. Co., Boston.

Xia X. and Zhang J. (2010a). Energy efficiency and control systems-from a POET perspective, in: IFAC Conference on Control Methodologies and Technology for Energy Efficiency, Vilamoura, Portugal, 29-31 March.
Xia X. and Zhang J. (2010b). Energy audit-from a POET perspective, in: International Conference on Applied Energy, 21-23 April, Singapore.

Xia X. and Zhang J. (2011). Modelling and control of heavy-haul trains, IEEE Control Systems Magazine, Vol. 31, No. 4, 18-24.

Received 7 September 2010; revised 3 June 2011 